\title{
A community randomised controlled trial evaluating a home-based environmental intervention package of improved stoves, solar water disinfection and kitchen sinks in rural Peru: Rationale, trial design and baseline findings ${ }^{\text {is }}$
}

\author{
S.M. Hartinger ${ }^{\text {a,b,c }}$, C.F. Lanata ${ }^{\text {c,d }}$, J. Hattendorf ${ }^{\text {a,b }}$, A.I. Gil ${ }^{\text {c }}$, H. Verastegui ${ }^{c}$, \\ T. Ochoa ${ }^{\mathrm{e}}$, D. Mäusezahl ${ }^{\mathrm{a}, \mathrm{b}, *}$ \\ a Swiss Tropical and Public Health Institute, P.O. Box, CH-4002 Basel, Switzerland \\ b University of Basel, Petersplatz $1 \mathrm{CH}-4003$ Basel, Switzerland \\ c Instituto de Investigación Nutricional, Av. La Molina 1885, Lima 12, Peru \\ d Universidad Peruana de Ciencias Aplicadas, Prolongación Primavera 2390, Monterrico Lima 33, Peru \\ e Instituto de Medicina Tropical Alexander Von Humbolt, Universidad Peruana Cayetano Heredia, Av. Honorio Delgado 430, Urb. Ingeniería, S.M.P. Lima 31, Peru
}

\section{A R T I C L E I N F O}

\section{Article history:}

Received 24 February 2011

Received in revised form 11 June 2011

Accepted 28 June 2011

Available online 6 July 2011

\section{Keywords:}

Community randomised trial

Diarrhoea

Acute lower respiratory infections

Hygiene

Hand-washing

Child health

\begin{abstract}
A B S T R A C T
Introduction: Pneumonia and diarrhoea are leading causes of death in children. There is a need to develop effective interventions.

Objective: We present the design and baseline findings of a community-randomised controlled trial in rural Peru to evaluate the health impact of an Integrated Home-based Intervention Package in children aged 6 to 35 months.

Methods: We randomised 51 communities. The intervention was developed through a community-participatory approach prior to the trial. They comprised the construction of improved stoves and kitchen sinks, the promotion of hand washing, and solar drinking water disinfection (SODIS). To reduce the potential impact of non-blinding bias, a psychomotor stimulation intervention was implemented in the control arm. The baseline survey included anthropometric and socio-economic characteristics. In a sub-sample we determined the level of faecal contamination of drinking water, hands and kitchen utensils and the prevalence of diarrhoegenic Escherichia coli in stool specimen.

Results: We enrolled 534 children. At baseline all households used open fires and $77 \%$ had access to piped water supplies. E. coli was found in drinking water in $68 \%$ and $64 \%$ of the intervention and control households. Diarrhoegenic E. coli strains were isolated from 45/139 stool samples. The proportion of stunted children was 54\%.

Conclusions: Randomization resulted in comparable study arms. Recently, several critical reviews raised major concerns on the reliability of open health intervention trials, because of uncertain sustainability and non-blinding bias. In this regard, the presented trial featuring objective outcome measures, a simultaneous intervention in the control communities and a 12month follow up period will provide valuable evidence.
\end{abstract}

(c) 2011 Elsevier Inc. All rights reserved.

\footnotetext{
Thial registry: http://www.controlled-trials.com/ ISRCTN28191222.

* Corresponding author at: Dept. Public Health and Epidemiology, Swiss Tropical and Public Health Institute, P.O. Box, CH-4002 Basel, Switzerland. Tel.: + 41 61 2847178 ; fax: + 41612848105 .

E-mail addresses: Stella.Hartinger@unibas.ch (S.M. Hartinger), clanata@iin.sld.pe (C.F. Lanata), Jan.Hattendorf@unibas.ch (J. Hattendorf), agil@iin.sld.pe (A.I. Gil), hverastegui@iin.sld.pe (H. Verastegui), Theresa.J.Ochoa@uth.tmc.edu (T. Ochoa), Daniel.Maeusezahl@unibas.ch (D. Mäusezahl).
} 


\section{Introduction}

Acute respiratory infections and diarrhoea are leading causes of child mortality worldwide [1]. It was estimated that half of the annual deaths due to lower respiratory infections and $80 \%$ of the diarrhoea attributable mortality are linked to environmental risk factors, such as indoor air pollution due to incomplete combustion [1,2] and inadequate access to safe water supply, sanitation facilities and hygiene [3]. Air pollution due to incomplete combustion of biomass fuels account for $2.9 \%$ of worldwide deaths per year, and for $3.7 \%$ of the overall disease burden in developing countries [4]. Similarly, unsafe water and sanitation account for $9 \%$ and under nutrition is the estimated underlying cause for one third of under-five mortality [5].

Under-five child mortality due to preventable conditions, such as improving water, sanitation and hygiene, and indoor and outdoor air pollution became a global priority [6]. Several low cost, efficient and effective interventions, such as providing running water within the kitchen area, improving water quality through household water treatment and washing hands using soap are acceptable interventions in most communities. They contribute effectively to the prevention of diarrhoeal diseases and the transmission of acute lower respiratory infection (ALRI) [7-10]. A recent systematic review provided evidence that hand washing with soap can reduce child diarrhoea by $48 \%$, and the risk to acquire a diarrhoeal illness can be reduced by $17 \%$ and $36 \%$ through adequate household water treatments (HWT) and improved sanitation [11]. Similarly it has been shown that simple indoor air quality interventions reduce disease burden for ALRI [4]. Biomass fuel smoke contains a large range of healthdamaging pollutants that can cause mucous membrane irritation and aggravate respiratory diseases by reducing the resistance to infection $[12,13]$. A recent meta-analysis determined a pooled odds of disease of 1.8 for children exposed to cooking with solid fuels $[14,15]$.

According to the WHO country profile, 19\% of Peru's environmental burden could be prevented by environmental improvements [16]. Several "improved stoves" programmes of government and NGO were developed to reduce indoor air pollution as environmental health hazard $[17,18]$. However, stoves come in a variety of designs and their efficiency in reducing children's respiratory problems has not always been evaluated [19]. In addition to the national stove improvement programme, several large scale programmes were implemented to increase piped water and sanitation in rural Peruvian populations $[17,20]$.

We developed an Integrated Home-based Intervention Package (IHIP) to improve unsafe drinking water and hygienic conditions and indoor air pollution from biomass fuel combustion. In an extended community participatory approach we developed a home-based environmental intervention package comprising an improved, ventilated stove to reduce indoor air pollution; a kitchen sink to increase water and kitchen hygiene and a solar disinfection home-based water treatment (HWT) to improve drinking water quality [21]. The hardware interventions were complemented with a hand washing-with-soap and kitchen hygiene educational component to enhance potential effects to reduce acute child diarrhoeal and respiratory infections diseases and their effects on child growth. We describe the design and baseline characteristics of a community-randomised controlled intervention trial to evaluate the effectiveness of an IHIP.

\section{Methods}

\subsection{Study area and population}

The study was conducted in the San Marcos Province, Cajamarca region, northern Peru. We selected this area for its number of well separated accessible rural communities, and because no health related intervention programmes were currently being implemented. Most of the local residents were small-scale farmers, living in small houses with earthen floors and adobe walls, with three or more persons sleeping in the same room and with traditional stove or open fire for cooking. To identify eligible rural communities and households with children aged 6-35 months, trained field worker conducted a house-to-house preliminary screening between March and June 2008 and identified an initial group of 56 rural communities complying to the following criteria: i) no access to potable water and sewage systems, ii) the majority of the population used biomass fuel for cooking and heating, and iii) were located in a 90-minute drive range away from the project office in San Marcos town.

\subsection{Trial design}

We implemented a community-randomised controlled field trial to evaluate the efficacy of the IHIP interventions on reducing the rate of acute diarrhoeal illness, acute lower respiratory infection and child growth in children aged 6 to 35 months at enrolment over a 12 month surveillance period. Morbidity surveillance started after all IHIP-interventions were in place (February 2009).

Due to the nature of the intervention, blinding was not possible. As a strategy to reduce non-blinding bias, a child psychomotor development intervention was implemented in the control arm as an equivalent to the IHIP in the intervention arm. Psychomotor development of children in both arms was evaluated using a standardised and validated assessment tool used by national authorities. For balancing the intensity of the contact at the household level over the 12month surveillance period motivational and monitoring follow-up procedures including morbidity, anthropometric and psychomotor evaluations were done in both study arms at similar a rate of recurrence.

A household was considered eligible for the study if the following criteria were met: a) at least one child aged 6 to 35 months living in the home, b) using wood or solid fuel as main energy source for cooking, c) not being connected to public sewage, and d) tenants planning to stay in their home for the next 12 months. A household was excluded if a) the child had any congenital abnormalities or suffered from a chronic debilitating illness, and b) families that had two or more households in different geographical areas with migration within sites that lasted more than 6 months during the year (mainly for migratory agriculture practices). 


\subsection{Sample size}

Sample size was calculated using the method of Hayes and Bennett [22]. Given that national sources indicated similar disease rates for child diarrhoea and ALRI of 5 episodes per child per year [23], we aimed of detecting a 33\% absolute reduction in the annual diarrhoeal and ALRI incidence rate in children (from 5 to 3.33 episodes per child, intervention compared to control study arm) with an $80 \%$ power at a $5 \%$ level of significance. This required a minimum of 10 person- years of observation in each cluster. Considering a coefficient of between-cluster variation ( $\mathrm{k}$ ) of 0.2 we needed 9 villages each in the intervention and control arm. To adjust for loss to follow up of individual households, incomplete longitudinal data and a dropout rate of up to two villages per study arm, we arrived at a final sample size of 22 communities (11 in each arm) with 30 children each. The census identified 56 eligible communities. Three communities had less than three households with children in the required age range. These communities were annexed to their nearest neighbouring

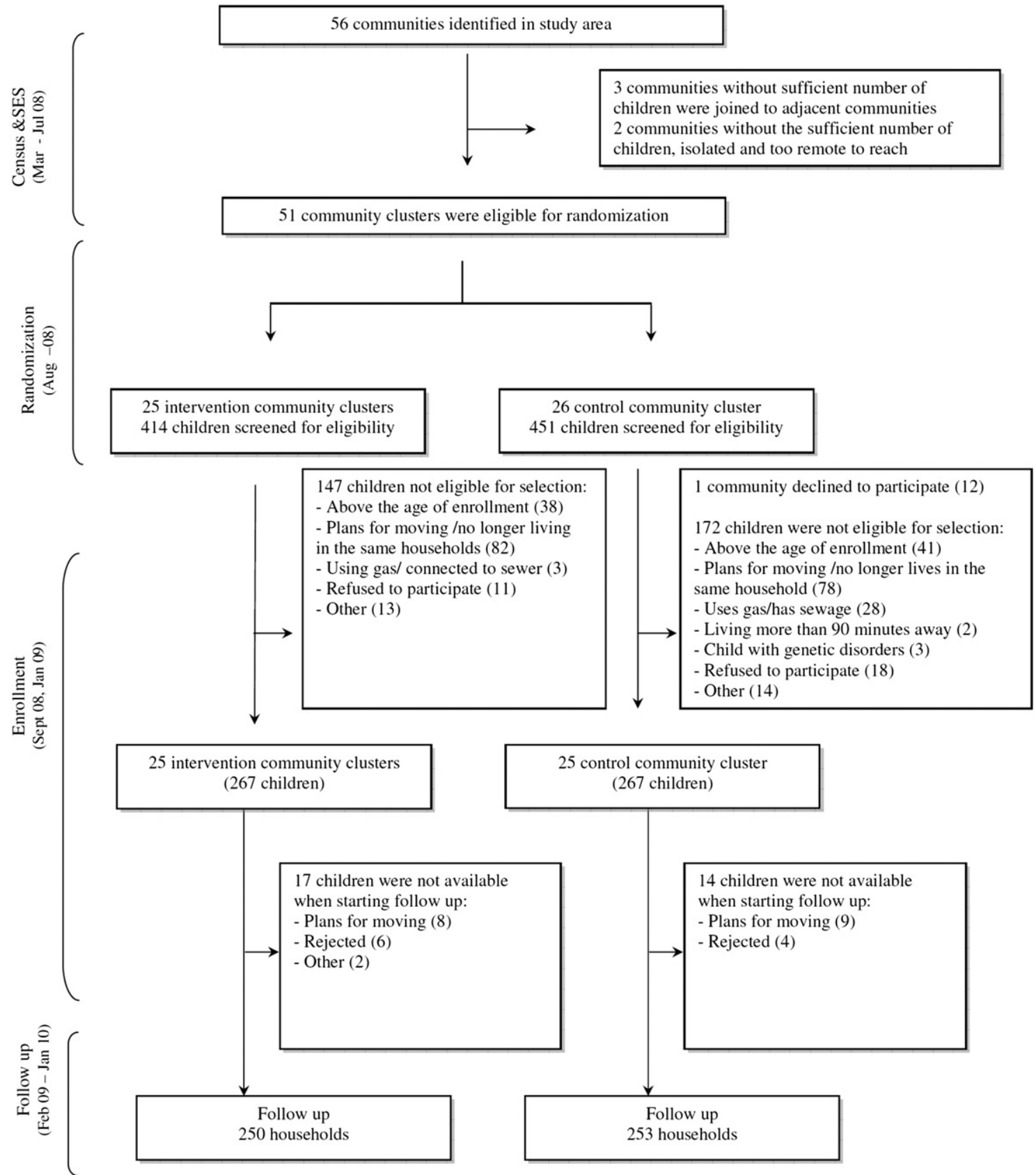

Fig. 1. Flow diagram of a community randomised controlled trial of a home based indoor air, drinking water and hygiene intervention package in rural Peru. 
community for randomisation. Two communities had insufficient number of children and were too remote to reach and were, thus, excluded. Hence, 51 communities remained eligible for randomisation (Fig. 1).

The number of eligible households per community was much lower than expected (Fig. 1). We decided to randomise all communities and to enrol all eligible and consenting households with eligible children. The minimum cluster size was defined as four children per cluster. The number of children in the 51 community clusters available for randomization ranged from four to 29 children per cluster. An updated sample size calculation revealed that the new number of clusters would be sufficient to detect a reduction of $22 \%$ incidence reduction assuming a minimum of 5 personyears of observation in each cluster keeping all other parameters constant.

\subsection{Randomization}

We allocated the 51 communities to the intervention arms by using covariate-based constrained randomization as proposed by Moulton [24]. Prior to randomization the communities were stratified by terciles of median land surface owned by eligible households. Out of the $1.4 \times 10^{14}$ possible allocation sequences we identified those who satisfied the following restriction criteria: a) the difference between the number of participating children in the intervention and the control arm should be less than two in each stratum, b) the median of the caretakers' total years of schooling in each community should not differ by more than one year in each stratum. The difference in the proportion of households within each village that c) are Catholics, d) have electric supply and e) are farmers should be less than 20 percentage points in each stratum. From the $4.7 \times 10^{11}$ combinations that fulfilled these criteria, one was randomly selected as final allocation sequence. Subsequently, we randomly selected 400 additional restricted sequences, to examine how often two specific villages appeared together in the same study arm to ensure that all villages were independent of each other. We chose relaxed constraints (i.e. differences) to ensure a proper randomization process where all experimental units would be truly independent from each other. The restriction variables were chosen as they were likely to be linked to the socio-economic status and were expected to show heterogeneity among the 51 communities.

\subsection{Enrolment}

Upon the randomization of the communities, participants were enrolled between September 2008 and January 2009 after updating our census database with the information on new eligible children that had come to age. We included new households that currently had children 6 to 35 months of age living permanently in the house. If more than one eligible child was found in a household, we randomly selected one for study participation. One parent, usually the mother, signed a written informed consent after trained field workers explained the study in detail.

\subsection{Morbidity surveillance and field data acquisition}

\subsubsection{Health outcomes}

Primary outcomes are diarrhoea, defined as the passage of three or more liquid or semi-liquid stools in a 24-hour period or the passage of at least one liquid or semi-liquid stool with blood or mucus [25], acute lower respiratory infections defined as a child presenting with cough or difficulties with breathing with a raised respiratory rate on two consecutive measurement [26]; and stunting, wasting and underweight defined as below -2 Z-scores of the WHO growth standards curves.

We also assessed the frequency of reported symptoms of child cough, fever medical treatment seeking and compliance using the interventions. In a sub-sample of subjects in both arms we investigated the total coliforms and E. coli analysed from drinking water, mother's hands and kitchen cloths/sponges and stool samples collected from diarrhoea-symptomatic and -asymptomatic children.

\subsubsection{Measuring health outcomes}

Trained field workers visited each household weekly and collected morbidity data from the mother or caretaker about the daily occurrence of signs and symptoms of child diarrhoea and respiratory illnesses. In order to detect respiratory infections, the mother was asked a set of screening questions. If the child had cough and/or fever the day of the exam or in the last $48 \mathrm{~h}$, additional diagnose questions linked to severity symptoms (noisy breathing, rhonchus/wheezing, fast breathing rates, malaise, lack of appetite, lower chest in-draw) were asked. Field worker were instructed to obtain two measurements of respiratory rates, which increase the specificity for a diagnosis of pneumonia without a loss of sensitivity [27].

Severely ill children with diarrhoea, cough and/or fever and with elevated respiratory rates and any other signs of severity for those conditions, were referred to the local health care centre for free evaluation and treatment.

Anthropometric measurements were collected every two months. Lengths/heights and weights of children were taken by two trained field workers during home visits, using digital scales (Robusta 813 SECA) sensitive to $0.1 \mathrm{~kg}$ and portable wood length boards ( $1 \mathrm{~cm}$ scale with $\mathrm{mm}$ increments). All measurements were taken three times, using the arithmetic mean for analysis. We placed the scales on a flat wooden board levelled for horizontal position.

\subsubsection{Socioeconomic survey}

Field workers implemented a baseline socio-demographic survey to obtain information on household demographics, education, family composition, economic characteristics and general home-, kitchen- and water management. The information was used to classify study households according to national poverty indicators called "unsatisfied basic need indicators" of the national statistical office [28]. Five basic need components were assessed: 1) inappropriate infrastructural characteristics (dirt floors or mud/stone walls); 2) crowding; 3) lack of access to basic sanitation; 4) having at least one child in school age not attending school; and 5) family head with incomplete elementary school level education and with at least three dependants. Applying the national poverty classification indicators, any household that had one 
unsatisfied basic need was considered "poor". The lack of more than one basic need determines the level of poverty [28].

\subsubsection{Environmental exposure measurements}

In order to evaluate the microbial quality of the drinking water, hands and kitchen utensils, trained field workers collected samples at baseline, midterm and at the end of the surveillance period, thus covering data collection during dry and wet season. All samples were collected between 7am and $12 \mathrm{pm}$ and were carried in a cooled, insulated envelope to the project laboratory. Samples were stored at 4 to $8{ }^{\circ} \mathrm{C}$ and processed on the day of collection. Mothers' hands and kitchen cloths/sponges were analyzed for total coliforms and E. coli using PetrifilmTM EC plates applying standard methods [29]. Results for kitchen cloths/sponges were expressed as colony-forming units per $\mathrm{cm}^{2}\left(\mathrm{CFU} / \mathrm{cm}^{2}\right)$. Water samples were analyzed for thermo-tolerant (faecal) coliforms using a membrane filtration method OXFAM-DELAGUA. Results were expressed as colony-forming units per $100 \mathrm{ml}$ of water (CFU/100 ml). All samples were double-read by two microbiologists, if the reading had more than $10 \%$ difference in counts a third microbiologist was consulted for a final decision.

\subsubsection{Stool specimen tests}

Stool samples from diarrhoea-symptomatic and asymptomatic children were collected. All diarrhoea-symptomatic stool specimens were collected from children that presented signs and symptoms of diarrhoea during the day of the weekly visit. Additionally, we collected stool specimens from 100 randomly selected healthy children, 50\% in each intervention arm at baseline, midterm and at the end of the surveillance period. Field workers were instructed to collect the samples and place them in sterile plastic containers and transport them in a cooled envelope to the field laboratory the same day. Stool specimens were stored in Cary Blair transport media and refrigerated at $-20^{\circ} \mathrm{C}$. Stool and environmental samples were analyzed to detect diarrhoeagenic E. coli. Every three weeks all Carry Blair tubes were transported to the Nutritional Research Institute (IIN) laboratory in Lima. Samples were inoculated onto MacConkey agar plates and after incubation E. coli-like colonies were isolated for further testing. Five colonies per sample for either coliforms or E. coli were saved in peptone media vials, and later transported to a specialised laboratory for analysis using real time PCR multiplex system [30]. The PCR method detected virulence genes of enterotoxigenic (ETEC), enteroinvasive (EIEC), enteropathogenic (EPEC), Shigatoxin producing (STEC), entero-adherent (EAEC) and diffuselyadherent E. coli (DAEC) [30].

\subsubsection{Spot check observations}

To reinforce the intervention messages and gather compliance data, two additional groups of field workers visited the study households monthly. They conducted spot observations about the usage of improved stove, hand washing, application of SODIS, kitchen hygiene and environment, the use of the psychomotor stimulation tools in the control arm and compliance overall.

\subsection{Design and implementation of the main interventions}

\subsubsection{The IHIP home-based intervention package}

To develop the intervention package, we conducted a series of qualitative and quantitative explorations on people's needs and preferences for specific smoke reduction and drinking water treatment devices [21]. We also tested personal (hands, stool specimen) and kitchen-environmental samples for faecal contaminations in an exploratory study carried out in adjacent communities to the study site [31]. Those studies led to the development of a new stove OPTIMA, combined with a kitchen sink and solar disinfection as a HWT and the development of kitchen hygiene education [32]. As part of the hygiene messages we promoted hand-washing and the elimination of animal excreta and isolation of animals from the kitchen environment.

Education messages were re-enforced monthly by field workers in both study arms. Mothers in the IHIP group were instructed to keep their kitchen environment clean, to wash their hands and children's hands ideally with soap or detergent after defecation, after changing diapers, before food preparation, before eating and before feeding infants and small children and. Additionally, mothers were instructed in the correct use of the improved stoves including cleaning and removing ashes and wood residues that could obstruct the ventilation. The correct application of the SODISmethod was also encouraged. Mothers from the control arm were trained in the correct use of the early stimulation toys and were urged to engage their children at least 30 min every day.

\subsubsection{Intervention in the control arm}

To counteract potential dropout and non-blinding bias in the control study arm, a psychomotor stimulation intervention focusing on early child development, - hence unrelated to the IHIP- was selected. This intervention was adapted from the government-based WawaWasi National Programme, which provides early age stimulation to children under four-years of age at day-care centres [33]. Together with WawaWasi experts, we adapted the intervention to be used at household level. Mothers were trained in the use of the early stimulation toys and materials. They were instructed to play and encourage their children at least 30 min every day. The baseline and end of study evaluation were done using the psychomotor development evaluation tool from the WawaWasi programme. This evaluation was conducted with children from both study arms and lasted about 30-45 min testing seven levels of child development: basic habits, personal and social development, gross and fine motor skills, relationship between objects, space and time and communication. Each area was assessed with a different set of interactive toys and materials.

\subsection{Baseline assessment}

We conducted a baseline survey between May and August 2008 collecting socio-economic and demographic household characteristics. To understand the occurrence of faecal contamination and the presence of diarrhoegenic E. coli strains at the outset, we tested kitchen utensils, mothers' and children's hands, drinking water and collected stool 
specimens from diarrhoea-symptomatic and asymptomatic children. Additionally anthropometric measurements of children in our study were obtained. Childhood psychomotor development was also assessed in all children in our study at baseline (data not presented).

\subsection{Ethics}

The study was approved by the Nutritional Research Institute Ethical Review Board and the cantonal ethical review board of University of Basel, Switzerland (Ethikkommission Beider Basel, EKBB). The Cajamarca Regional Health Authority and the Peruvian National Institute of Health (INS) also approved the trial which was nationally registered with INS and with the ISRCTN (ISRCTN28191222). Community leaders and local authorities from the study area signed a collaborative agreement with the IIN before study implementation. The mother/caretaker or father of each study child signed a written informed consent form.

\section{Results}

\subsection{Recruitment}

A total of 865 households (414 intervention- and 451 control arm) from 51 communities were screened for eligibility (Fig. 1). Of those 38\% (147 households in the intervention, 184 in the control arm) did not meet all inclusion criteria or refused to participate. Additionally, one community randomised to the control arm refused to participate. In total, we enrolled 534 households of 50 community clusters into the study; 267 households in 25 clusters per study arm. Between enrolment and the start of the evaluation study period, i.e. the follow-up phase (Feb 2009), 31 households were lost (17 and 14 in the intervention and control arms). A total of 503 households, 250 in the intervention and 253 in the control arm started the follow-up phase.

\subsection{Baseline characteristics}

We obtained demographic and socio-economic household characteristics information from 534 households, 261 (97\%) of the intervention arm and 251 (94\%) control households. Both study arms were balanced according to these characteristics (Table 1). The mean number of persons living in each household was five for the intervention arm and 4.6 for the control arm. Caretakers mean age was 30 years in the intervention arm and 29 years in the control arm. The educational level for mothers and household heads for both study arms was similar. Some $73 \%$ and $81 \%$ of the households in the intervention and control arm had a piped water system with a faucet available in the household's yard; the others collected their water from open wells or unprotected water sources. The proportion of stunted children was 54\%, underweight $6 \%$. Wasting was rarely observed (Table 1 ).

\subsection{Household microbial contamination}

A total of 870 samples of drinking water, kitchen utensils and mother's hands were collected, 414 in the intervention
Table 1

Demographic and socio-economic characteristics of 534 households in rural Peru.

\begin{tabular}{|c|c|c|c|c|c|c|}
\hline \multirow[t]{2}{*}{ Characteristics } & \multicolumn{3}{|c|}{ Intervention arm } & \multicolumn{3}{|c|}{ Control arm } \\
\hline & $\mathrm{N}$ & $\begin{array}{l}\text { Mean } \\
\text { or \% }\end{array}$ & SD & $\mathrm{N}$ & $\begin{array}{l}\text { Mean } \\
\text { or } \%\end{array}$ & SD \\
\hline \multicolumn{7}{|l|}{ Demography } \\
\hline Child sex (female) & 267 & $47 \%$ & & 266 & $49 \%$ & \\
\hline Child age & 266 & 2.0 & 0.7 & 266 & 2.0 & 0.7 \\
\hline Children $<1$ year & 266 & $9 \%$ & & 266 & $9 \%$ & \\
\hline Female headed households & 261 & $3 \%$ & & 263 & $7 \%$ & \\
\hline Age of caretaker & 217 & 30 & 7.8 & 223 & 29 & 7.7 \\
\hline \multicolumn{7}{|l|}{ Maternal education } \\
\hline None & 261 & $9 \%$ & & 251 & $4 \%$ & \\
\hline Primary level & 261 & $25 \%$ & & 251 & $30 \%$ & \\
\hline Secondary level & 261 & $4 \%$ & & 251 & $8 \%$ & \\
\hline Higher degrees & 261 & $2 \%$ & & 251 & $0.4 \%$ & \\
\hline Years of education & 227 & 4 & 1.7 & 228 & 4.1 & 1.7 \\
\hline $\begin{array}{l}\text { Agriculture as main activity of } \\
\text { family head }\end{array}$ & 261 & $81 \%$ & & 251 & $69 \%$ & \\
\hline \multicolumn{7}{|l|}{ Household assets } \\
\hline Motorcycle & 261 & $2 \%$ & & 251 & $0.4 \%$ & \\
\hline Vehicle (tractor, car) & 261 & $0.7 \%$ & & 251 & $0.4 \%$ & \\
\hline Radio & 261 & $86 \%$ & & 251 & $90 \%$ & \\
\hline Bicycle & 261 & $18 \%$ & & 251 & $19 \%$ & \\
\hline Television & 261 & $17 \%$ & & 251 & $24 \%$ & \\
\hline Cell phone & 261 & $14 \%$ & & 251 & $19 \%$ & \\
\hline \multicolumn{7}{|l|}{ Household characteristics } \\
\hline Household with latrines & 261 & $80 \%$ & & 251 & $83 \%$ & \\
\hline Piped water supply & 261 & $73 \%$ & & 251 & $81 \%$ & \\
\hline Water from well or stream & 261 & $19 \%$ & & 251 & $12 \%$ & \\
\hline Electricity & 261 & $15 \%$ & & 251 & $18 \%$ & \\
\hline \multicolumn{7}{|l|}{ Anthropometry } \\
\hline Stunting $^{\mathrm{a}}$ & 196 & $56 \%$ & & 194 & $52 \%$ & \\
\hline Wasting ${ }^{\mathrm{a}}$ & 182 & $1 \%$ & & 183 & $0 \%$ & \\
\hline Underweight $^{\mathrm{a}}$ & 201 & $5 \%$ & & 202 & $6 \%$ & \\
\hline
\end{tabular}

a Below -2 Z-scores of the median WHO growth standards.

and 456 in the control arm. The frequency of contamination with total coliforms and $E$. coli was similar between study arms (Table 2). Kitchen cloths/sponges were the most frequently contaminated kitchen utensils. About two third of all drinking water samples were found positive for E. coli. Seventy two percent of all samples grew coliforms and were further tested for diarrhoegenic E. coli. Drinking water, kitchen wipes and mother's hands, were contaminated with no difference between study arms (Table 3 ). The most common type of diarrhoegenic E. coli were EPEC (2\%) and $\operatorname{EAEC~(2\% )}$ in all samples tested.

\subsection{Stool samples}

A total of 46 diarrhoeal specimens were collected, 24 in the intervention and 22 in the control arm (Table 4). A total of 93 specimens from healthy children were obtained. Overall the most frequent type of diarrhoegenic $E$. coli found was EPEC (11\%), followed by EAEC (9\%) and ETEC (9\%). The proportion of diarrhoegenic E. coli infection was 39\% in the intervention arm and 25\% in the control arm. Diarrhoegenic E. coli was more frequently isolated in diarrhoeic specimens than in stools samples of healthy children in both study arms. 
Table 2

Total coliforms and E. coli contamination of drinking water and main kitchen hygiene indicators (percentages [\%] and geometric means [GM]).

\begin{tabular}{|c|c|c|c|c|c|c|c|c|}
\hline \multirow[t]{3}{*}{ Sample type } & \multirow{2}{*}{\multicolumn{2}{|c|}{$\begin{array}{l}\text { Total coliforms } \\
\%(\mathrm{~N})\end{array}$}} & \multirow{2}{*}{\multicolumn{2}{|c|}{$\begin{array}{l}\text { Concentration of total } \\
\text { coliforms } \\
\text { GM }\end{array}$}} & \multirow{2}{*}{\multicolumn{2}{|c|}{$\begin{array}{l}\text { E. coli } \\
\%(\mathrm{~N})\end{array}$}} & \multirow{2}{*}{\multicolumn{2}{|c|}{$\begin{array}{l}\text { Concentration of E. coli } \\
\mathrm{GM}\end{array}$}} \\
\hline & & & & & & & & \\
\hline & Intervention & Control & Intervention & Control & Intervention & Control & Intervention & Control \\
\hline Drinking water ${ }^{\mathrm{a}}$ & NA & NA & NA & NA & $68(88)$ & $64(94)$ & 0.9 & 1.2 \\
\hline Mother's hand ${ }^{\mathrm{b}}$ & $81(95)$ & 86 (109) & 15.2 & 20.9 & 27 (95) & 22 (109) & 1.4 & 1.3 \\
\hline Kitchen cloth $^{c}$ & $95(45)$ & $100(38)$ & 48.8 & 55.8 & $31(45)$ & $31(38)$ & 1.2 & 1.1 \\
\hline Kitchen sponge ${ }^{c}$ & $82(11)$ & $82(11)$ & 4.2 & 61.4 & $36(11)$ & $9(9)$ & 1.2 & 0.6 \\
\hline Spoon $^{d}$ & $40(77)$ & $61(80)$ & 1.4 & 2.1 & $1(77)$ & $10(80)$ & 0.5 & 0.6 \\
\hline Plate $^{\mathrm{d}}$ & 37 (97) & $56(121)$ & 1.3 & 2.6 & $3(97)$ & $8(121)$ & 0.5 & 0.6 \\
\hline Bottle nipple $^{d}$ & $100(1)$ & $100(3)$ & NA & NA & $0(1)$ & $0(3)$ & NA & NA \\
\hline
\end{tabular}

a Colony forming units (CFU)/100 ml.

b $\mathrm{CFU} /$ hands.

c $\mathrm{CFU} / 10 \times 10 \mathrm{~cm}$ sampling surface.

d CFU/area in contact with food or drink.

\section{Discussion}

Cluster randomised trials are considered the gold standard to determine the effect of health interventions. We selected a cluster randomization instead of an individual randomization of households, to avoid problems of cross-contamination between neighbouring households assigned to different

Table 3

Frequency of isolated diarrhoegenic E. coli of drinking water and main kitchen hygiene indicators.

\begin{tabular}{|c|c|c|c|c|c|c|c|c|}
\hline Intervention & $\mathrm{N}$ & EPEC & STEC & EIEC & EAEC & ETEC & DAEC & $\begin{array}{l}\text { All } \\
\text { positives }\end{array}$ \\
\hline $\begin{array}{c}\text { Drinking } \\
\text { water }\end{array}$ & 60 & 4 & 0 & 0 & 3 & 0 & 0 & $12 \%$ \\
\hline $\begin{array}{c}\text { Mother's } \\
\text { hand }^{\mathrm{a}}\end{array}$ & 87 & 2 & 3 & 0 & 0 & 0 & 0 & $6 \%$ \\
\hline $\begin{array}{c}\text { Kitchen } \\
\text { cloth }\end{array}$ & 39 & 1 & 0 & 2 & 0 & 0 & 0 & $8 \%$ \\
\hline $\begin{array}{l}\text { Kitchen } \\
\text { sponge }\end{array}$ & 12 & 0 & 0 & 0 & 0 & 0 & 0 & $0 \%$ \\
\hline Spoon & 37 & 0 & 0 & 0 & 0 & 1 & 0 & $3 \%$ \\
\hline Plate & 49 & 0 & 0 & 0 & 0 & 2 & 1 & $6 \%$ \\
\hline $\begin{array}{l}\text { Bottle } \\
\text { nipple }\end{array}$ & 2 & 0 & 0 & 0 & 0 & 0 & 0 & $0 \%$ \\
\hline Control & $\mathrm{N}$ & EPEC & STEC & EIEC & EAEC & ETEC & DAEC & $\begin{array}{l}\text { All } \\
\text { positives }\end{array}$ \\
\hline $\begin{array}{c}\text { Drinking } \\
\text { water }\end{array}$ & 63 & 4 & 0 & 0 & 2 & 0 & 0 & $10 \%$ \\
\hline $\begin{array}{c}\text { Mother's } \\
\text { hand }\end{array}$ & 106 & 0 & 1 & 1 & 5 & 1 & 0 & $8 \%$ \\
\hline $\begin{array}{l}\text { Kitchen } \\
\text { cloth }\end{array}$ & 19 & 1 & 0 & 0 & 0 & 1 & 0 & $11 \%$ \\
\hline $\begin{array}{l}\text { Kitchen } \\
\text { sponge }\end{array}$ & 8 & 0 & 0 & 0 & 0 & 0 & 0 & $0 \%$ \\
\hline Spoon & 52 & 0 & 0 & 2 & 0 & 0 & 0 & $4 \%$ \\
\hline Plate & 75 & 0 & 1 & 0 & 1 & 0 & 0 & $3 \%$ \\
\hline $\begin{array}{l}\text { Bottle } \\
\text { nipple }\end{array}$ & 0 & 0 & 0 & 0 & 0 & 0 & 0 & $0 \%$ \\
\hline
\end{tabular}

$\mathrm{EPEC}=$ Enteropathogenic E. coli.

STEC = Shiga toxin-producing E. coli.

EIEC = Enteroinvasive E. coli.

$\mathrm{EAEC}=$ Enteroaggregative E. coli.

$\mathrm{ETEC}=$ Enterotoxigenic E. coli.

DAEC $=$ Diffusely adherent $E$. coli.

a One sample with mixed contamination EAEC and ETEC. study arms in an open trial. Non-blinded trials have the advantage that community level dynamics for adoption allow for a natural diffusion. Only households that complied with the enrolment criteria received the intervention, but, scaling up activities and handover workshops will approach stakeholders and stimulate families to replicate the IHIP at the end of the study.

Recent reviews, meta-analyses and discussions identified non blinding, sustainability and subjective outcomes as critical issues [34-36]. Non-blinding bias might be a serious problem in intervention and in control communities. Field workers who collected the data will be aware of the interventions and could possible introduce courtesy bias. Only few blinded placebo controlled trials on home based drinking water treatment in resource limited settings are published in the peer reviewed literature [37-39], all of them found no or only small health effects. Unfortunately, the current debate $[36,40]$ remains silent about the fact that a placebo controlled trial will underestimate the true effect of the intervention, because blinding would negatively affect compliance and inhibit the community dynamics, both of which are known to play a significant role in the process of

Table 4

Diarrhoegenic E. coli isolated from stool samples of children between 6 and 36 months of age.

\begin{tabular}{lllllllll}
\hline Intervention & $\mathrm{N}$ & EPEC & STEC & EIEC & EAEC & ETEC & DAEC & $\begin{array}{l}\text { All } \\
\text { positives }\end{array}$ \\
\hline $\begin{array}{c}\text { Healthy } \\
\text { children }\end{array}$ & 47 & 6 & 1 & 2 & 3 & 5 & 0 & $36 \%$ \\
$\begin{array}{c}\text { Ill children } \\
\text { Control }\end{array}$ & 24 & 2 & 0 & 1 & 5 & 3 & 0 & $45 \%$ \\
$\begin{array}{c}\text { Healthy } \\
\text { children }\end{array}$ & 46 & 2 & 0 & 0 & 3 & 3 & 1 & $\begin{array}{l}19 \% \\
\text { Ill children }\end{array}$ \\
\hline
\end{tabular}

$\mathrm{EPEC}=$ Enteropathogenic E. coli.

STEC $=$ Shiga toxin-producing E. coli.

EIEC $=$ Enteroinvasive E. coli.

$\mathrm{EAEC}=$ Enteroaggregative E. coli

$\mathrm{ETEC}=$ Enterotoxigenic E. coli.

DAEC $=$ Diffusely adherent $E$. coli.

a One sample with mixed contamination EPEC and ETEC. 
adaptation of new methods [41]. Recently, Boisson et al. [39] published the results of a double-blinded placebo controlled trial to assess the effect of water filter devices in the field. After eight months almost none of the participants drank filtered water exclusively. We believe that the true impact lies between the estimates of blinded and open trials.

Consequently, we choose an open design and tried to minimise non-blinding bias. All data collection instruments were standardised, all study workers were thoroughly trained and data collection was done by an independent team of field workers, which was not part of the initial education and re-enforcement of the interventions during the follow-up period. Furthermore, the selection of a psychomotor stimulation package in the control arm was fully based on a strongly expressed felt need, - like the IHIP intervention -, and aimed at reducing non-blinding bias and drop-out rates in this trial arm. However, financial and logistical reasons allowed implementing the psychomotor package only in the intervention arm. It would have been ideal to test the IHIP intervention against a psychomotor stimulation intervention in both trial arms to make the control intervention a true counterfactual. On the other hand we are also convinced that the participants in the intervention arm would have been overstrained with too many different messages and activities. Falling short introducing the control intervention in both trial arms the potential impact of the psychomotor stimulation on the primary outcomes would underestimate a potential effect of the IHIP-intervention.

Trials using only subjective outcomes are more susceptible to bias. Thus, and to reduce potential bias due to the lack of blinding, we collected data on a variety of objective outcomes including respiratory rates, weight gain, child growth, environmental samples (water, mothers' hands and kitchen cloths), stool samples from ill and healthy children in addition to subjective outcome measures such as mother/ caretakers' assessment of illness and disease.

The use of longitudinal prevalence measures for diarrhoeal or respiratory infections has recently been argued for [36]. We chose incidence rather than longitudinal prevalence (LP) as outcome measure in order to best deal with large variations of episode duration - a key constraint to use LP-, and with the recurrent character of our two primary outcomes. The use of LP and monthly outcome measurements is further constraint as the authors illustrate the need to considerably increase sample size maintaining the same power of the study [36]. We concur with Zwane and colleagues that frequent contacts and measurements may influence illness reporting and, thus, potentially bias intervention effects [42]. However, given the features of our interventions and household surveillance in both study arms we believe that any potentially resulting bias will be balanced.

The one-year follow-up surveillance period in our study is substantially longer compared to the median follow-up period of about 6 months in other studies [35]. Studies with shorter follow-up periods indicated higher health impacts and higher compliance levels, which is consistent with the evidence that the effectiveness of the interventions clearly declines with the duration of the follow-up [35]. Possible reasons for this decline are that participants stop using the interventions; the interventions start to fail for technical or other reasons, or reporting fatigue in long follow-up studies especially for reporting of subjective outcomes. Thus, sustainability and adherence are key factors for the intervention. We learned in our community work and in other studies $[21,43,44]$, that good health is not always the convincing entry point and motivation to foster and strengthen adoption at the home level, e.g. time gain, social status and cost reduction, are other important perceived improvements and, hence, drivers for adoption. Thus, and in discussing those issues all interventions in this trial were selected in a community participatory approach, to ensure compliance [21]. Preliminary work revealed several key components necessary for adherence e.g. the availability of water in the kitchen environment was suggested by the participants they considered that it would help improve hand-washing and home hygiene - thus it was included as part of the IHIP.

There are several limitations to the study. First, the interventions were delivered in a package format and hence, there is no clear way to differentiate the impact of each individual intervention on the decrease of diarrhoea episodes and prevalence due to household water treatment (solar disinfection of drinking water and kitchen cloths), water availability (kitchen sinks), and hand washing health education messages. Time- and financial constraints did not allow adopting a factorial design to adequately estimate the synergies, and sample size would have needed to be substantially increased to detect significant interactions.

The combined household burden of disease from indoor air pollution, contaminated drinking water and from poor food- and kitchen hygiene in rural Peru is particularly high. The characteristics of the study households are typical of rural households in Peru. However, some differences were found when comparing our data to the national census [28] and the national Demographic and Family Health Survey [45]. The proportion of households with piped water system in the yard was remarkably higher than the proportion reported from rural Peru (71\% versus 22\%). We also found a higher percentage of latrines ( $87 \%$ versus $47 \%$ ) and the use of wood as a main fuel source for cooking (99\% versus $77 \%$ ) comparing study households to overall rural Peru rates. These differences are due to a more successful implementation of these national programmes in the Cajamarca region. Anthropometric measurements indicate show no significant differences between stunting, wasting and under nutrition between study arms, and showed that our results were comparable to national statistics [45].

Considering the national poverty criteria based on the "unsatisfied basic needs indicator", our population had a substantially higher classification of "poor" households for rural populations than reflected in national figures $(99.5 \%$ versus $49.5 \%$ respectively) [28]. Because this national poverty classification gives special importance to structural components and has equal weight for all components, our population, was more frequently allocated to the "poor" category in that classification system due to the lack of adequate household infrastructure and education. Additionally the "poor" category varies depending on the geographical regional: $46.2 \%$ of the rural coastal area of Peru mainly composed of peri-urban slums populations is considered poor, compared to $43.5 \%$ of the Andean region (our study site), and $70.7 \%$ of the rain forest region. 
This community-randomised control trial including 51 communities is one of the few trials that combine well documented effective interventions into a single package. We have demonstrated that the IHIP-combined intervention package meets significant local needs and is a feasible intervention in the Peruvian Andes; our next challenge will be to determine its effectiveness in reducing childhood illnesses.

\section{Author contributions}

The principal investigators: Drs Mäusezahl and Lanata had full access to the data and take responsibility for the integrity of the data and accuracy of the data analysis.

Study concept and design: Mäusezahl, Lanata

Obtained funding: Mäusezahl, Lanata

Acquisition of data: Hartinger, Lanata, Gil, Verastegui

Implementation of public health interventions: Hartinger, Lanata, Gil, Verastegui

Analysis and interpretation of data: Hartinger, Lanata, Hattendorf, Gil, Verastegui, Ochoa, Mäusezahl.

Drafting of the manuscript: Hartinger, Mäusezahl, Lanata, Hattendorf

Critical revision of the manuscript for important intellectual content: Gil, Verastegui

Statistical analysis: Hartinger, Hattendorf, Verastegui

\section{Potential conflicts of interest of the authors}

None declared.

\section{Role of the sponsor}

This study received financial support of the UBS Optimus Foundation, through a grant given to the IIN and Swiss TPH. The sponsors had no role in the design and conduct of the study; collection, management, analysis, and interpretation of the data; or preparation, review, or approval of the manuscript.

\section{Acknowledgements}

The authors wish to express their appreciation and thank the study families for their kind participation and the local authorities for their continuous support. We also express our gratitude to the field teams, especially to Mr. Roger Abanto and Mr. Concepcion Sanchez who designed and installed the Optima stoves and kitchen sinks in the intervention communities. We also appreciate the untiring work by Ines Pineda in the microbiology field laboratory in San Marcos.

\section{References}

[1] Black RE, Cousens S, Johnson HL, Lawn JE, Rudan I, Bassani DG, et al. Global, regional, and national causes of child mortality in 2008: a systematic analysis. Lancet 2010;375:1969-87.

[2] WHO. Fuel for life: household energy and health. Geneva: World Health Organization; 2006.

[3] Prüss-Ustün A, Bos R, Gore F, Bartram J. Safer water, better health. Cost, benefits and sustainability of interventions to protect and promote health. Geneva: World Health Organization; 2008.
[4] Bruce N, Perez-Padilla R, Albalak R. Indoor air pollution in developing countries: a major environmental and public health challenge. Bull World Health Organ 2000;78:1078-92.

[5] Victora CG, Adair L, Fall C, Hallal PC, Martorell R, Richter L, et al. Maternal and child undernutrition: consequences for adult health and human capital. Lancet 2008;371:340-57.

[6] Victora CG, Black RE, Boerma JT, Bryce J. Measuring impact in the Millennium Development Goal era and beyond: a new approach to large-scale effectiveness evaluations. Lancet 2011;377:85-95.

[7] Bowen A, Ma H, Ou J, Billhimer W, Long T, Mintz E, et al. A clusterrandomized controlled trial evaluating the effect of a handwashingpromotion program in Chinese primary schools. Am J Trop Med Hyg 2007;76:1166-73.

[8] Schmidt W, Cairncross S, Barreto ML, Clasen T, Genser B. Recent diarrhoeal illness and risk of lower respiratory infections in children under the age of 5 years. Int J Epidemiol 2009;38:766-72.

[9] Rudan I, El Arifeen S, Black RE, Campbell H. Childhood pneumonia and diarrhoea: setting our priorities right. Lancet Infect Dis 2007;7:56-61.

[10] Aiello AE, Coulborn RM, Perez V, Larson EL. Effect of hand hygiene on infectious disease risk in the community setting: a meta-analysis. Am J Public Health 2008;98:1372-81.

[11] Cairncross S, Hunt C, Boisson S, Bostoen K, Curtis V, Fung ICH, et al. Water, sanitation and hygiene for the prevention of diarrhoea. Int $\mathrm{J}$ Epidemiol 2010;39(Suppl 1):i193-205.

[12] Smith KR, Samet JM, Romieu I, Bruce N. Indoor air pollution in developing countries and acute lower respiratory infections in children. Thorax 2000;55:518-32.

[13] Fullerton DG, Bruce N, Gordon SB. Indoor air pollution from biomass fuel smoke is a major health concern in the developing world. Trans $\mathrm{R}$ Soc Trop Med Hyg 2008;102:843-51.

[14] Dherani M, Pope D, Mascarenhas M, Smith KR, Weber M, Bruce N. Indoor air pollution from unprocessed solid fuel use and pneumonia risk in children aged under five years: a systematic review and metaanalysis. Bull World Health Organ 2008;86:390-398C.

[15] Rehfuess EA, Tzala L, Best N, Briggs DJ, Joffe M. Solid fuel use and cooking practices as a major risk factor for ALRI mortality among African children. J Epidemiol Community Health 2009;63:887-92.

[16] Environmental burden of disease: country profiles [Internet]. Geneva: World Health Organization; 2010 . Available from http://www.who.int/ quantifying_ehimpacts/countryprofiles/en/.

[17] Programa Sembrando [Internet]. Lima. Proyecto Sembrando. 2007 [cited 2010 Sep 29]. Available from: http://www.sembrando.org.pe/.

[18] Programa de Desarrollo Agropecuario PROAGRO [Internet]. La PAz. Deutsche Gesellschaft für Technische Zusammenarbeit (GTZ) GmbH. Coorperacion Tecnica Alemana; 2005-2010. [cited 2010 Sep 29]. Available from http://www.endev-bolivia.org/.

[19] HEDON Household Energy Network [Internet]. HEDON. [updated 2010 Nov 10, cited 2011 Jan 10]. Available from http://www.hedon.info/.

[20] Programa de Agua para Todos. Ministerio de Vivienda, Construcción y Saneamiento [Internet]. Lima: Ministerio de Vivienda, Construcción y Saneamiento; 2007-2009. [cited 2010 Sep 30]. Available from http:// www.vivienda.gob.pe/Direcciones/saneamiento_programas.aspx.

[21] Hartinger SM, Lanata CF, Gil AI, Flores SM, Verastegui H, Hattendorf J, et al. Combining interventions: improved stoves, kitchen sinks and solar disinfection of drinking water and kitchen clothes to improve home hygiene in rural Peru. Unpublished results.

[22] Hayes RJ, Bennett S. Simple sample size calculation for clusterrandomized trials. Int J Epidemiol 1999;28:319-26.

[23] Lanata CF. Incidencia y evalucion de la nuemonia en niños a nivel comunitario. Infecciones Respiratorias en Niños. Washington, D.C: Organización Panamericana de la Salud; 1997.

[24] Moulton LH. Covariate-based constrained randomization of grouprandomized trials. Clin Trials 2004;1:297-305.

[25] Baqui AH, Black RE, Yunus M, Hoque AR, Chowdhury HR, Sack RB. Methodological issues in diarrhoeal diseases epidemiology: definition of diarrhoeal episodes. Int J Epidemiol 1991;20:1057-63.

[26] Lanata CF, Rudan I, Boschi-Pinto C, Tomaskovic L, Cherian T, Weber M, et al. Methodological and quality issues in epidemiological studies of acute lower respiratory infections in children in developing countries. Int J Epidemiol 2004;33:1362-72.

[27] Lanata CF, Black RALRI. Nutrition and health in developing countries. New Jersey (NJ): Humana Press; 2008. p. 179-214.

[28] Instituto Nacional de Estadística e Informática (INEI) [Internet]. Lima INEI; 2007[cited 2010 Oct 1]. Available from http://www.inei.gob.pe/.

[29] WHO. Guidelines for drinking-water quality: incorporating the 1st and 2nd addenda, Vol. 1, recommendations. 3rd ed. Geneva, Switzerland: WHO Press, World Health Organization; 2008.

[30] Barletta F, Ochoa TJ, Ecker L, Gil AI, Lanata CF, Cleary TG. Validation of five-colony pool analysis using multiplex real-time PCR for detection of diarrheagenic Escherichia coli. J Clin Microbiol 2009;47:1915-7. 
[31] Gil A, Lanata CF, Hartinger S, Maeusezahl D, Padilla B, Ochoa T], et al. Faecal contamination of food, water, hands and kitchen utensils at household level in rural areas of Peru. Unpublished results.

[32] The SODIS Foundation- Welcome to our Website [Internet]. cited 2010 Sep 30];Available from http://www.fundacionsodis.org/web/index. php?lang $=$ en.

[33] Programa Nacional WAWAWASI [Internet]. Lima. Ministerio de la Mujer y Desarrollo Social. 2008 [updated 2008 Dec; cited 2010 Sep 30]; Available from: http://www.mimdes.gob.pe/programas/wawawasi. html.

[34] Wood L, Egger M, Gluud LL, Schulz KF, Jüni P, Altman DG, et al. Empirical evidence of bias in treatment effect estimates in controlled trials with different interventions and outcomes: meta-epidemiological study. BMJ 2008;336:601-5.

[35] Hunter PR. Household water treatment in developing countries: comparing different intervention types using meta-regression. Environ Sci Technol 2009;43:8991-7.

[36] Schmidt W, Cairncross S. Household water treatment in poor populations: is there enough evidence for scaling up now? Environ Sci Technol 2009;43:986-92.

[37] Jain S, Sahanoon OK, Blanton E, Schmitz A, Wannemuehler KA, Hoekstra $\mathrm{RM}$, et al. Sodium dichloroisocyanurate tablets for routine treatment of household drinking water in periurban Ghana: a randomized controlled trial. Am J Trop Med Hyg 2010;82:16-22.

[38] Kirchhoff LV, McClelland KE, Do Carmo Pinho M, Araujo JG, De Sousa MA, Guerrant RL. Feasibility and efficacy of in-home water chlorination in rural North-eastern Brazil. J Hyg (Lond) 1985;94:173-80.
[39] Boisson S, Kiyombo M, Sthreshley L, Tumba S, Makambo J, Clasen T. Field assessment of a novel household-based water filtration device: a randomised, placebo-controlled trial in the Democratic Republic of Congo. PLoS One 2010;5:e12613.

[40] Clasen T, Bartram J, Colford J, Luby S, Quick R, Sobsey M. Comment on "Household water treatment in poor populations: is there enough evidence for scaling up now?". Environ Sci Technol 2009;43:5542-4 author reply 5545-5546.

[41] Moser S, Mosler H. Differences in influence patterns between groups predicting the adoption of a solar disinfection technology for drinking water in Bolivia. Soc Sci Med 2008;67:497-504.

[42] Zwane AP, Zinman J, Van Dusen E, Pariente W, Null C, Miguel E, et al. Being surveyed can change later behavior and related parameter estimates. Proc Natl Acad Sci 2011;108:1821-6.

[43] Boisson S, Schmidt W, Berhanu T, Gezahegn H, Clasen T. Randomized controlled trial in rural Ethiopia to assess a portable water treatment device. Environ Sci Technol 2009;43:5934-9.

[44] Mäusezahl D, Christen A, Pacheco GD, Tellez FA, Iriarte M, Zapata ME, et al. Solar drinking water disinfection (SODIS) to reduce childhood diarrhoea in rural Bolivia: a cluster-randomized, controlled trial. PLoS Med 2009;6:e1000125.

[45] Encuesta Demográfica y de Salud Familiar 2007-2008. [Internet].Lima: Instituto Nacional de Estadistica e Informatica; 2009. [cited 2010 Sep 30]. Available from http://desa.inei.gob.pe/endes/endes2007/Publicaci \%C3\%B3n\%20ENDES.html. 